\title{
The relationship between motivation orientations and competitive anxiety in Bocce players: Does gender make a difference
}

\author{
Mutlu TURKMEN ${ }^{1}$, Taner BOZKUS ${ }^{1}$, Atahan ALTINTAS ${ }^{2}$ \\ ${ }^{1}$ Physical Education and Sports School, Bartin University, Turkey \\ ${ }^{2}$ Sport Sciences Department, Baskent University, Ankara, Turkey
}

\section{Email addresses:}

turkmenm@yahoo.com(M. TURKMEN), tanerbozkus@yahoo.com(T. BOZKUS), atahanaltintas@gmail.com(A. ALTINTAS)

\section{To cite this article:}

Mutlu TURKMEN, Taner BOZKUS, Atahan ALTINTAS. The Relationship Between Motivation Orientations and Competitive Anxiety in Bocce Players: Does Gender Make a Difference. Psychology and Behavioral Sciences. Vol. 2, No. 4, 2013, pp. 162-168. doi: $10.11648 /$ j.pbs.20130204.12

\begin{abstract}
This study investigated the relationship between motivation orientations and anxiety levels of Bocce players, and gender differences in this relationship. A total of 88 Bocce players (47 female, 41 male) participated to this study voluntarily. All the players completed "Sport Competitive Anxiety Test (SCAT)" and "Sport Motivation Scale (SMS)" test. The data was evaluated using SPSS 19.0, through arithmetic means $(\bar{X})$, standard deviation (SD), t-test, and correlation analyses. For the statistical significance, $\mathrm{p}$ value was taken as $0.05(\mathrm{p}<0.05)$. Results revealed that female players were more intrinsically motivated, while exhibiting less external regulation and less amotivation than male players. Female players were also observed to have slightly higher competitive anxiety level than males. According to the results of t-test, there were significant differences between female and male players in external regulation and amotivation levels, but none of the intrinsic motivation subscale was statistically significant. Besides, there was no significant difference in competitive anxiety levels of female and male Bocce players. Results also showed that there was no correlation between motivation orientations sub-scales and competitive anxiety. In conclusion, female players had higher score than male players in intrinsic motivation and competitive anxiety, but lower score in external regulation and amotivation.
\end{abstract}

Keywords: Motivation Orientations, Intrinsic Motivation, Extrinsic Motivation, Amotivation, Competitive Anxiety, Bocce

\section{Introduction}

There has been a real boost in the studies of sport psychology during the last four decades. Many of the researchers have focused on various aspects of sport psychology including concentration, motivation, anxiety, personality, relaxation, imagery, etc. in order to find out the best conditions to reach psychological well-being of the athletes.

This study included two main subjects of sport psychology: competitive anxiety and motivation orientations, and tried to explore the relationship between them. Both subjects have vital importance for the competitor athletes in order to have successful results in their sport life. Highly increased motivation results with a stressful situation which is called anxiety, and when it is not controlled within logical limits it will lead to some other psychosomatic and depressive disorders. What's more anxiety is one of the personality traits which can be applied to each person individually [1]. The exaggerated worries and expectations that cause anxiety would also result with many physical symptoms such as muscle tension, headaches, stomach cramps, and more frequent urination. Therefore there is a significant relation between athletic performance, anxiety and motivation.

For the first time it was Martens who defined the anxiety in sport context as competitive anxiety [2]. He relied on Speilberger's notion of trait anxiety and developed the concept of competitive trait anxiety as a sport-specific issue. He defined competitive trait anxiety as the tendency to perceive competitive situations as threatening and to respond to these situations with feelings of apprehension and tension. Thus, people with a high level of trait anxiety will perceive competitive situations as threatening and will thereby experience higher degrees of anxiety in such situations. But the apprehensive response to specific competitive situations is called competitive state anxiety. 
This state is generally similar to state anxiety with a difference that the stimulus for anxious response is always a sport situation [2].

Competitive anxiety directly affects the athletic performance, and the higher it goes up, the lower will be the athletic performance [3]. It is thus of utmost importance to examine the factors causing anxiety in athletes, and alternative methods to control and decrease the level of anxiety.

Another important issue in sport psychology is motivation, which is also supposed to have close connections with anxiety. Therefore it is important to try to find out the relations and interactions of these two issues within the same case studies.

Deci and Ryan [4] divided motivation into three major parts and conceptualized it as a continuum moving from high to low self-determination as one proceeds from intrinsic motivation, to extrinsic motivation and then amotivation. On the other hand amotivation is the relative absence of motivation, while intrinsic motivation is the engagement in an activity for its own sake $[5,6]$.

Intrinsic motivation refers to being engaged in an activity for itself, out of interest, and for the pleasure and satisfaction derived simply performing this activity [4]. In the context of sport participation, the intrinsic motivation shows that the athlete participating to a specific sport finds this sport interesting and enjoyable, and also is satisfied with what he learns and does.

On the other hand extrinsic motivation, contrary to intrinsic motivation, attributes to a variety of behaviors where the goals of the action extend beyond those inherent in the activity itself. Thus, the athlete participating to a specific sport to show off, to gain prestige in society, to recover from pressure, or to earn a specific award is extrinsically motivated. The divisional conceptualization of motivation as intrinsic - extrinsic has been proven to be valid in different life domains, including physical education and sport domain [4,7].

On the other hand when there is absence of any self-determination, this is called amotivation [4]. Amotivation can also be simply defined as the lack of both intrinsic and extrinsic motivation [6]. So in amotivation there is no reason for the person to participate to the activities.

The main division as intrinsic and extrinsic also has sub-divisions. In extrinsic motivation, from higher to lower levels of self determination, they are named as external regulation, introjected regulation, and identified regulation. Generally external regulation is associated with the extrinsic motivation, and conveys the behaviors regulated through external means such as rewards and constraints. Introjected regulation occurs when the external contingencies become internalized and individuals force themselves to perform the activity. Finally, the identified regulation occurs when the individual comes to judge and value the behavior as very important, therefore should be performed out of choice.
The intrinsic motivation is also divided into three types: intrinsic motivation to know, to accomplish things, and to experience stimulation. The first shows the pleasure of learning and knowing through participation, the second shows the pleasure of engaging and doing activities, and the last shows the pleasure of experiencing stimulating sensations. So it can be said that the athletes, who are in search of excitement, are intrinsically motivated to experience stimulation.

In the light of the theoretical information presented above, the main purpose of this study was to explore the relationship between competitive anxiety and motivation orientations, separately intrinsic, extrinsic motivations and amotivation. Another main purpose of this study was to find out the gender differences in competitive anxiety and motivation orientations of Bocce players. Past research has many times revealed gender differences under specific conditions and in some sub-scales of motivational orientations and competitive anxiety levels of athletes [3,7-16].

Most of the case studies in sport psychology so far have concentrated on mainly anxiety. Researchers criticized the strong tendency, especially in the applied setting, to focus on anxiety only. In many studies it was pointed out that wider range of emotions of athletes should be studied in order to find out better conditions to promote athletes' psychological well-being, so that they can achieve better results in competitions $[17,18]$.

There were some studies which had concentrated on the relation between motivational climate and anxiety. These studies have shown possible relations to the cognitive components of anxiety [19-21]. Some other studies have also shown that cognitive and somatic anxiety have differing relations with other variables, such as quality of motor performance, cognitive processing, and psycho-physiological measures [22,23]. It is important to know which anxiety components are influenced by a given intervention [24].

The literature has so far conveyed that personality factors are dominant on intrinsic motivation. Thus different sports, even different tasks in the same sport may attract different types of personalities [25]. The decision to participate in particular activities and the sensations experienced are dictated to some extent by stable individual differences [26]. Thus, the relationship between personality, motivation orientations and competitive anxiety is also an important issue which should be studied in longitudinal case researches.

To date, no studies have been reported that specifically look at the relationship between motivation orientations sub-scales and competitive anxiety. In the literature reviewed above, there were few studies that investigated the motivation and anxiety within the same contextual frame, but none of them significantly focused on their relationship. However, there was a similar study which was conducted in EFL teaching context, and concentrated on the relations between language learning anxiety, motivation, and gender [27]. 


\section{Material and Methods}

The present research is descriptive-correlational in which the relationship between the orientation variables and competitive anxiety, and gender factor is analyzed in accordance with the research purpose.

\subsection{Sample Group}

In this research Bocce players are chosen as the sample group. Bocce, known as Boules or Petanque in French and Bowls in English, has been a popular sport in Turkey during last 8 years after the establishment of national federation in 2005. Bocce is a very typical sport, as it includes both individual and team competitions, and has traditional strategic games played against opponent teams, and fast flowing, endurance and strength demanding disciplines played against time [28]. Thus, it would represent both individual and team sports and require both mental and physical competencies. Therefore the findings of this study would normally be applicable to more sport disciplines.

Participants included 88 volunteers (47 girls and 41 boys) from Turkish primary division Bocce league. The players from 18 clubs, who participated to primary league first phase in 2012-2013 season, were all exceptionally included in the research. The age and gender distribution of the players is presented in Table 1 .

Table 1. Gender and age distribution of the sample group

\begin{tabular}{llll}
\hline & $\mathbf{n}$ & $\bar{X}$ (age) & SD (years) \\
\hline Male & 41 & 23.09 & 11.80 \\
Female & 47 & 19.46 & 7.46 \\
Total & 88 & 21.15 & 9.83 \\
\hline
\end{tabular}

\subsection{Data Gathering Tools}

All the players completed Sport Motivation Scale Test (SMS) and Sport Competitive Anxiety Test (SCAT).

Sport Motivation Scale Test (SMS): This test, which is valid and reliable to measure sport motivation, was developed by Pelletier et al. in 1995 [29], and includes 28 items as reply to the question: "Why do you practice sport?" The test is composed of 7 subscales assessing the 7 motivational constructs, as following: 3 types of intrinsic motivation (intrinsic motivation to know, to accomplish things, and to experience stimulation), 3 types of extrinsic motivation (external, introjected, and identified regulation), and amotivation. Each item is ranked with a 7 point likert scale, ranging from 1 (does not correspond at all) to 7 (corresponds exactly).

Sport Competitive Anxiety Test (SCAT): This test, which was developed by Martens [2] to find out the anxiety levels of athletes during competition, was composed of 15 items. 10 of the items in the test are related to the anxiety, and 5 extra items were added in order to decrease the level of subjectivity of the answers. Questions were answered with 3 different expressions; "never, sometimes, often".

Although the SCAT has proven to be a valuable research instrument, it is criticized by many researchers as it measures primarily somatic anxiety [30]. Still many of the researchers prefer it as the primary data gathering instrument. That's why this study also preferred to apply SCAT in data gathering.

Here it is also noteworthy to refer to some previous researchers who were critical about all sport competitive anxiety tests. The first source of problems pertains to the construct validity of current anxiety measures [18]. These tests have been suspected to confound anxiety with positive excitement [31]. It also does not provide clear information of whether and to what extent an athlete perceives a competition as a threat or a challenge [18].

In order to reach optimal validity in the test results, the players were asked to fill in the anxiety test at least 30 minutes before the competition as suggested by the previous researchers [32].

\subsection{Data Analyses}

The data derived from these 2 tests were evaluated using the Statistical Package for the Social Sciences (SPSS) version 19.0 through arithmetic means $(\bar{X})$, standard deviation (SD) and independent samples t-test. Besides correlational analyses were conducted with sex, age, and the motivational dimensions and anxiety to explore the relationships between them. For the statistical significance, $\mathrm{p}$ value was taken as $0.05(\mathrm{p}<0.05)$.

\section{Findings}

The results of SCAT and SMS tests are presented in Table 2 below. According to these results, female players demonstrated more intrinsic motivation $(\bar{X}=5.10 \& 5.14)$ and more introjected regulation $(\bar{X}=5.02)$ than male players ( $\bar{X}=4.96,4.75 \& 4.87)$, while displaying less external regulation $(\bar{X}=3.90)$ and less amotivation $(\bar{X}=2.96)$ than male players $(\bar{X}=4.48 \& 3.43)$. On the other hand the identified regulation levels of both groups appeared to be almost equal ( $\bar{X}=4.68 \& 4.65)$.

When it comes to the competitive anxiety levels, female players were observed to have slightly higher average $(\bar{X}=19.80)$ than males $(\bar{X}=18.17)$.

According to the results of t-test, there were significant differences between female and male players in external regulation $(\mathrm{t}=-2.01)$ and amotivation $(\mathrm{t}=-1.76)$. None of the intrinsic motivation subscale was found to be statistically significant. Besides, there was no significant difference in competitive anxiety levels of female and male Bocce players. 
Table 2. The comparison of motivation orientations and competitive anxiety levels of the athletes according to gender variability

\begin{tabular}{llllll}
\hline & FEMALE & & MALE & t \\
& $\bar{X}$ & SD & $\bar{X}$ & SD & \\
\hline Motivation orientations: & & & & & .52 \\
Intrinsic - knowledge \& accomplishment & 5.10 & 1.03 & 4.96 & 1.40 & 1.38 \\
Intrinsic - stimulation & 5.14 & 1.12 & 4.75 & 1.56 & $-2.01^{*}$ \\
External regulation & 3.90 & 1.38 & 4.48 & 1.27 & .11 \\
Identified regulation & 4.68 & 1.21 & 4.65 & 1.50 & .51 \\
Introjected regulation & 5.02 & 1.36 & 4.87 & 1.47 & $-1.76^{*}$ \\
Amotivation & 2.96 & 1.03 & 3.43 & 1.47 & \\
Anxiety levels: & & & & & \\
Competitive anxiety & 19.80 & 4.72 & 18.17 & 4.12 & 1.71 \\
\hline
\end{tabular}

$* \mathrm{p}<0.05$

Table 3. Correlation between motivation orientations sub-scales and competitive anxiety

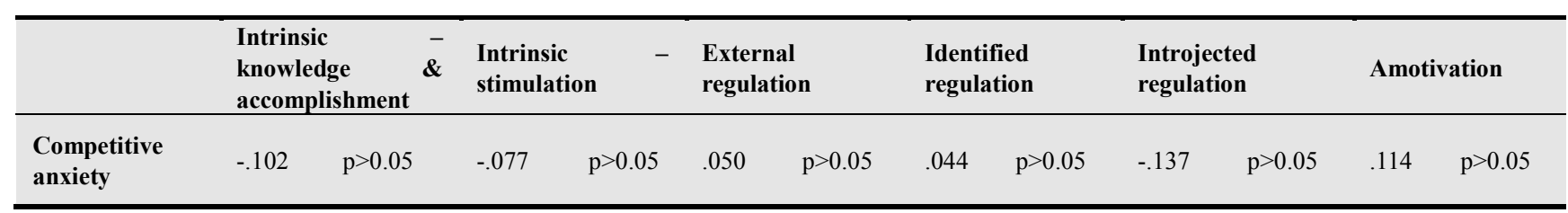

Table 4. Correlation between motivation orientations sub-scales, competitive anxiety, and age and gender

\begin{tabular}{lllllllllllllllllll}
\hline & $\begin{array}{l}\text { Intrinsic } \\
\text { knowledge } \\
\text { accomplishment }\end{array}$ & $\begin{array}{l}\text { \& } \\
\text { stimulation }\end{array}$ & $\begin{array}{l}\text { Intrinsic } \\
\text { regulation }\end{array}$ & $\begin{array}{l}\text { Identified } \\
\text { regulation }\end{array}$ & $\begin{array}{l}\text { Introjected } \\
\text { regulation }\end{array}$ & Amotivation & $\begin{array}{l}\text { Competitive } \\
\text { anxiety }\end{array}$ \\
\hline Age & -.056 & $\mathrm{p}>0.05$ & -.148 & $\mathrm{p}>0.05$ & $-.211^{*}$ & $\mathrm{P}=.048$ & -.013 & $\mathrm{p}>0.05$ & -.055 & $\mathrm{p}>0.05$ & .187 & $\mathrm{p}>0.05$ & -.182 & $\mathrm{p}>0.05$ \\
& & & & & & & & & & & & & & & \\
Gender & .138 & $\mathrm{p}>0.05$ & .100 & $\mathrm{p}>0.05$ & -.079 & $\mathrm{p}>0.05$ & .013 & $\mathrm{p}>0.05$ & .079 & $\mathrm{p}>0.05$ & .147 & $\mathrm{p}>0.05$ & $-.264^{*}$ & $\mathrm{P}=.013$ \\
\hline
\end{tabular}

$* \mathrm{p}<0.05$

The correlation analyses are presented in Table 3 and Table 4 above.

The correlation analyses between motivation orientations sub-scales and competitive anxiety conveyed that there was no correlation between them (Table 3 ).

When the motivation orientations sub-scales and competitive anxiety levels were examined according to the age and gender variables, it was found that age and external regulation, and gender and competitive anxiety were negatively correlated (Table 4).

\section{Discussion and Conclusions}

The study of anxiety, its antecedents, its relations with other psychological variables, and its consequences has a long history of theoretical and empirical attention within sport psychology [33,34].

Parallel to this empirical attention within sport psychology, this study also aimed to explore the motivation orientations and competitive anxiety levels of Bocce players, and to examine the relationship between them. A second purpose was to assess the gender differences.

In this study there was no correlation between motivation orientation sub-scales and competitive anxiety. This result is in line with the findings of previous studies in which task orientation of athletes had no significant relationship with their competitive anxiety $[21,33]$.

But there were some other studies which had found correlation between some motivation subjects and anxiety. In one of these studies in which the relationship between competitive anxiety, achievement goals, and motivational climates were studied, it came to the conclusion that there is significant relationship between task orientation and competitive anxiety of team athletes [12].

In another study, students who had high motivation profiles were found to have lower anxiety levels in physical education classes. Alternatively, the students of the low motivation profile demonstrated higher anxiety levels [35]. Similarly, another study on parent-coached children found out that there was correlation between achievement 
motivations and competitive state anxiety levels [36].

In another context, a study conveyed the relationship between motivation orientations and anxiety within reference to language learning [28]. According to this study, anxiety from helplessness and a negative attitude towards the English class negatively correlate with intrinsic motivation subscales and identified regulation, and it positively correlates with amotivation.

There would be differences between the findings of this study and other studies, as the characteristics of the studied groups are not similar to the sample of the present research. Still it is important to try to find a link between anxiety and motivation issues.

Examining the motivation orientations sub-scales and competitive anxiety levels according to the age and gender variables, it was found that age and external regulation, and gender and competitive anxiety were negatively correlated (Table 4). The negative correlation between age and external regulation can be understood easily, as younger athletes normally would be more affected with awards or constraints. When it comes to negatively correlated relation between gender and competitive anxiety, this finding should be examined carefully as no significant difference in competitive anxiety was found between sexes in t-test (Table 2 ). In the present study the findings of competitive anxiety and motivation orientations sub-scales has both parallel and contradictory results with the previous researches. Examining the competitive anxiety levels, although there was no significant difference between sexes, girls had higher scores which show that they experience anxiety slightly more than boys. This finding is totally in line with the previous researches $[12,14,15]$. In another study carried out on 458 talented young Dutch athletes, the male athletes outscored females in anxiety control [13]. This is because the boys in general have tendency to compete, but the girls to play. A study on adolescent students explored that the girls rated themselves as most competent in English and social activities and as least competent in sports, on the other hand the boys rated themselves as most competent, by a substantial margin, in sports [37]. Therefore all these results show that female athletes experience anxiety stronger than males although no significant difference was recorded.

So in general psychological skills differ between male and female athletes in elite sports [13]. In the present study it was shown that (Table 2) female players were more intrinsically motivated, but had less external regulation and amotivation when compared to male players. These findings are totally in line with previous studies $[8,9,29]$. But this study differs than many others as there is almost equality in identified regulation scores between female and male players. At his point it is important to note that the female and male players of this study shared the same teams and environmental conditions, which is totally different than in any other sports. Therefore, this mixed playing setting would decrease the differences expected between female and male players. In a recent study it is specially stressed that environmental factors and outcome variables affect motivation orientations in case studies [38].
As a result of this study, it would be valuable to underline that exclusive reliance on the findings of competitive anxiety and motivation orientations may lead misinterpretation of athletes' optimal psychological states. In fact, in the present study, the sub-scales of motivation orientations in general appeared to be more significant emotional states to the athletes than anxiety (Tables 2). Therefore it would be helpful to take motivation orientations into consideration in order to increase Bocce players' performance.

Before concluding, it is important to underscore two main limitations of this study. First, this study did not apply an experimental or longitudinal design including changes over time. Thus, it would not be appropriate to interpret the results in terms of a casual effect between motivation and anxiety. Secondly, as mentioned above, because the players share the same playing setting in the same teams, it is possible that the gender factor decreases as a result of continuous interaction. This may also help us understand why some motivation orientations subscales did not show significant difference. Therefore further studies should choose another sport and longitudinal-correlational research design in order to explore the relationship between motivation orientations and competitive anxiety.

\section{Acknowledgements}

The authors would like to thank to the players who participated to this study voluntarily, and also to their coaches who supported their participation. It is important to note that all the 88 players from 18 different clubs in Turkish primary division Bocce league participated to this study without any exception.

\section{References}

[1] G. Rodrigo, M. Lusiardo, and G. Pereira, "Relationship between anxiety and performance in soccer players", International Journal of Sport Psychology, 1990, 21, pp. 112-120.

[2] R. Martens, Sport Competition Anxiety Test. Champaign, IL: Human Kinetics. 1977.

[3] F. E. Abrahamsen, G. C. Roberts, and A. M. Pensgaard, "Achievement goals and gender effects on multidimensional anxiety in national level elite sport", Psychology of Sport and Exercise Science, 2008, 9, pp. 449-465.

[4] L. Deci and M. Ryan, Intrinsic motivation and self-determination in human behavior. New York: Plenum, 1985.

[5] M. Argyle, The social psychology of leisure. London: Penguin Books, 1996.

[6] K. Cockley, N. Bernard, D. Cunningham, and J. Motoike, “A psychometric investigation of the Academic Motivation Scale using a United States sample", Measurement and Evaluation in Counseling and Development Journal, 2001, 34, pp. 109-119. 
[7] R. J. Vallerand, E. L. Deci, and R. M. Ryan, "Intrinsic motivation in sport", in K. B. Pandolf (ed.) Exercise and Sport Sciences Reviews, Vol. 15, pp. 389-425, New York: Mc Millian, 1987.

[8] M. B. Andersen and J. H. Williams, "Gender role and sport competition anxiety: A re-examination", Research Quarterly for Exercise and Sport, 1987, 58 (1), pp. 52-56.

[9] R. J. Vallerand and R. Bissonnette, "Intrinsic, extrinsic, and motivational styles as predictors of behavior: A prospectus study", Journal of Personality, 1992, 60, pp. 599-620.

[10] M. S. Fortier, R. J. Vallerand, N. M. Briere, and P. J. Provencher, "Competitive and recreational sport structures and gender: a test of their relationship with sport motivation", International Journal of Sport Psychology, 1995, 26, pp. 24-39.

[11] J. L. Muth and T. F. Cash. "Body image attitudes: What difference does gender make?" Journal of Applied Social Psychology, 1997, 27, pp. 1438-1452.

[12] B. Gürbüz, A. Özkan, and F. H. Aşçı, "Genç sporcuların yarışma kaygı düzeylerinin cinsiyete ve spor deneyimine göre karşılaştırılması" (The comparison of competitive anxiety of young athletes according to gender and sport experience). Beden Eğitimi ve Sporda Sosyal Alanlar Kongresi Bildiriler Kitab1. 10-11 September 2003, Ankara: pp. 453-455, (in Turkish).

[13] M. T. Elferink-Gemser, C. Visscher, and K. A. P. M. Lammink, "Psychological characteristics of talented youth athletes in field hockey, basketball, volleyball, speed skating and swimming", in J. Gemser and P. Gemser (eds.), Today's talented youth field hockey players, the star of tomorrow? A study on talent development in field hockey, Groningen Studies in Sport Sciences 1, Groningen, 2005, pp. 87-101.

[14] K. Yıldız, O. Pepe, N. Sarıtaş, and E. Ö. Kaya, "An investigation on the levels of social anxiety according to gender variable in hearing-impaired adolescent athletes between 12-16 years old", Niğde Üniversitesi Physical Education and Sport Journal, 2012, 6(1), pp. 56-61.

[15] M. Turkmen, M. Kul, and T. Bozkuş, "Takım sporlarıyla uğraşan sporcuların yarışma kaygı düzeylerinin cinsiyete ve spor deneyimine gore incelenmesi", (Investigation of competitive anxiety levels of team athletes according to gender and sport experience), Uluslararası Hakemli Akademik Spor, Sağlık ve Tıp Bilimleri Dergisi, 2013, 3(7), pp. 106-112, (in Turkish).

[16] T. Bozkus, M. Turkmen, M. Kul, "The effects of age, sports experience and physical self perception on competition anxiety levels of female football players". International Journal of Academic Research Part B, 2013, 5(4), 509-513.

[17] Y. L. Hanin, Emotions in sport. Champaign, IL: Human Kinetics, 1999.

[18] E. Cerin, "Anxiety versus fundamental emotions as predictors of perceived functionality of pre-competitive emotional states, threat, and challenge in individual sports", Journal of Applied Sport Psychology, 2003, 15, pp. 223-238.

[19] C. Harwood and A. Swain, "The development and activation of achievement goals within tennis: II. A player, parent, and coach intervention", The Sport Psychologist, 2002, 16, pp. 111-137.
[20] A. Papaioannou and O. Kouli, "The effect of task structure, perceived motivational climate and goal orientations on students' ask involvement and anxiety". Journal of Applied Sport Psychology, 1999, 11, pp. 51-71.

[21] N. Ntoumanis and S. Biddle, "The relationship between competitive anxiety, achievement goals, and motivational climates", Research of Quarterly Exercise Sport, 1998, 69, pp. 176-187.

[22] D. Burton, "Measuring competitive state anxiety". In J. L. Duda (Ed.), Advances in sport and exercise psychology measurement (pp. 129-148). Morgantown, WV: Fitness Information Technology, 1998.

[23] R. E. Smith, F. L. Smoll, and M. W. Passer, "Sport performance anxiety in children and youth", In F. L. Smoll and R. E. Smith (Eds.), Children and youth in sports: A biopsychosocial perspective (2nd ed., pp. 501-536). Dubuque, IA: Kendall/Hunt, 2002.

[24] R. E. Smith, F. L. Smoll, and S. P. Cumming, "Effects of a motivational climate intervention for coaches on young athletes' sport performance anxiety", Journal of Sport and Exercise Psychology, 2007, 29, pp. 39-59.

[25] H. J. Eysenck, D. K. B. Nias, and D. N. Cox, "Sport and personality", Advances in Behavior Research and Therapy, 1982, 16, pp. 1-56.

[26] M. P. Schrader and D. L. Wann, "High risk recreation: The relationship between participant characteristics and degree of involvement", Journal of Sport Behavior, 1999, 22, pp. 426-441.

[27] T. Yashima, K. A. Noels, T. Shizuka, O. Takeuchi, S. Yamane, and K. Yoshizawa, "The Interplay of Classroom Anxiety, Intrinsic Motivation, and Gender in the Japanese EFL Context", Journal of Foreign Language Education and Research, 2008, 17, pp. 41-64.

[28] M. Turkmen, Bocce: Bowls, Petanque, Raffa and Boules -Definitions, History, and Rules-, Ankara: Neyir Yayincilik, 2011 (in Turkish).

[29] L. G. Pelletier, M. S. Fortier, R. J. Vallerand, K. M. Tuson, N. M. Brière, and M. R. Blais, "Toward a new measure of intrinsic motivation, extrinsic motivation, and amotivation in sports: The sport motivation scale", Journal of Sport and Exercise Psychology, 1995, 17, pp. 35-53.

[30] R. E., Smith, F. L. Smoll, and R. W. Schutz, "Measurement and correlates of sport-specific cognitive and somatic trait anxiety: The Sport Anxiety Scale", Anxiety Research, 1990, 2, pp. 263-280.

[31] G. Jones, "More than just a game: Research developments and issues in competitive anxiety in sport", British Journal of Psychology, 1995, 86, pp. 449-478.

[32] Lynette L. Craft, T. Michelle Magyar, Betsy J. Becker, and Deborah L. Feltz, "The relationship between the competitive state anxiety inventory-2 and sport performance: A meta-analysis", Journal of Sport and Exercise Psychology, 2003, 25, pp. 44-65.

[33] F. Behzadi, M. Hamzei, S. Nori, and M. H. Salehian, "The relationship between goal orientation and competitive anxiety in individual and team athletes fields", Annals of Biological Research, 2011, 2(6), pp. 261-268. 
[34] R.E. Smith, F. L. Smoll, S.P. Cumming, and J. R. Grossbard, "Measurement of multidimensional sport performance anxiety in children and adults: The sport anxiety scale-2", Journal of Sport and Exercise Psychology, 2006, 28, pp. 479-501.

[35] S. Y. Piipari, A. Watt, T. Jaakkola, J. Liukkonen, and J. E. Nurmi, "Relationships between physical education students' motivational profiles, enjoyment, state anxiety, and self-reported physical activity", Journal of Sports Science and Medicine, 2009, 8, pp. 327-336.

[36] H. Barber, H. Sukhi, and S. A. White, "The influence of parent-coaches on participant motivation and competitive anxiety in youth sport participants", Journal of Sport Behavior, June 1999, 22(2), pp. 162(1).

[37] J. Eccles, B. Barber, D. Jozefowicz, O. Malenchuk, and M. Vida, "Self-evaluations of competence, task values and self-esteem", in N. G Johnson, M. C. Roberts, and J. Worell (eds), Beyond appearance: A new look at adolescent girls, APA Washington DC, 1999, pp. 53-83.

[38] M. Próspero, A. C. Russell, and S. Vohra-Gupta, "Effects of motivation on educational attainment: Ethnic and developmental differences among first-generation students", Journal of Hispanic Higher Education, Feb 2012, 2(1), pp. 100-119. 